\title{
Alteração da capacidade funcional dos músculos da região abdominal: programa de treino "convencional" versus programa combinado de treino "convencional" e electroestimulação \\ Luísa Vieira1, Carlos Carvalho, Alberto Carvalho, Rui Garganta². \\ 1 - Instituto Superior da Maia, Maia, Portugal, \\ 2 - Faculdade de Desporto da Universidade do Porto, Porto, Portugal.
}

Vieira, L.; Carvalho, C.;Carvalho, A.; Garganta, $R$,; Alteração da capacidade funcional dos músculos da região abdominal: programa de treino "convencional" versus programa combinado de treino "convencional" e electroestimulação.Motricidade 3(2): 18-20

\section{Introdução}

O objectivo principal do presente estudo situase na procura dos melhores procedimentos para o desenvolvimento funcional da musculatura abdominal. Assim, pretendemos indagar se a utilização de electroestimulação poderá ser um factor de optimização do processo de treino, isto é, se os resultados são acrescidos quando ao treino convencional dos músculos abdominais se incluem contracções musculares induzidas electricamente.

\section{Objectivo}

Avaliar o efeito da electroestimulação testes de avaliação das diferentes expressões de força.

\section{Metodologia}

A amostra foi constituída por 28 alunos de Educação Física do ISMAI que foram distribuídos por 3 grupos: o grupo experimental 1 (GE1) que foi submetido a um programa de treino "convencional", o grupo experimental 2 (GE2), que realizou um programa combinado de treino "convencional" e electroestimulação e o grupo : de controlo (GC) que apenas realizou os testes de avaliação iniciais e finais. $O$ trabalho experimental decorreu durante 6 semanas com 2 UT $\stackrel{\infty}{\infty}$ semanais. Cada uma das sessões durava cerca de
90 minutos com uma parte de activação geral e um segmento principal realizado sob a forma de circuito em que ambos os grupos experimentais trabalhavam diferentes grupos musculares, mas com predominância dos músculos abdominais. Todos os elementos da amostra foram submetidos às medições do peso e altura e a testes de avaliação das diferentes expressões de força: (1) Situp "convencional", (2) Sit-up oblíquos, (3) Partial Curl-up e (4) Bent-knee Curl-up para avaliarmos a força resistência abdominal.

\section{Resultados}

Pela análise dos resultados constatou-se que, de uma maneira geral, existiram melhorias significativas na resistência localizada dos músculos abdominais do $1^{\circ}$ para o $2^{\circ}$ momento, nos diferentes testes dos grupos experimentais (tabela 1 ), mas tal não se verificou em relação ao grupo de controlo. Concretamente, em relação ao Sit-up "convencional" os ganhos foram de 3\% GC, 25\% GE1 e 9,1\% GE2. Relativamente ao Sit-up para os músculos oblíquos, os ganhos foram de $-4,3 \%$ GC, $11,8 \%$ GE1 e 9,3\% GE2. Nestes dois testes, só no GE1 esses ganhos foram estatisticamente significativos. 




Nos testes de Partial Curl-up e Bent-knee Curl-up ambos os grupos experimentais evidenciaram alterações estatisticamente significativas. Objectivamente, de $12,5 \%$ GE1 versus $13,2 \%$ GE2 para o primeiro teste; no segundo, de 15,5\% GE1 versus $11,6 \%$ GE2.

\section{Discussão}

Para a análise comparativa

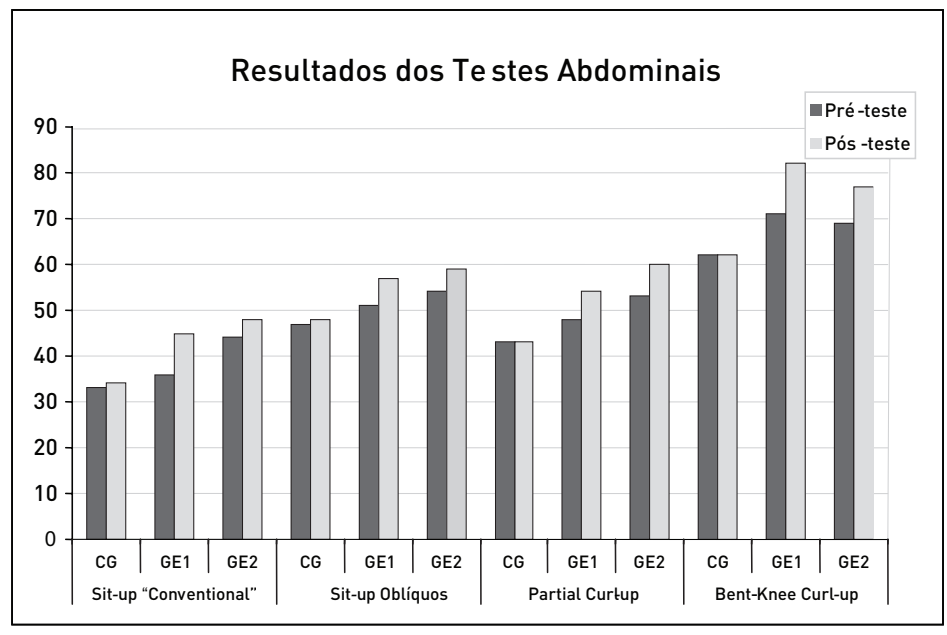

Figura 1: Resultados das alterações entre o $1^{\circ}$ e o $2^{\circ}$ momento, entre grupos, em cada variános diferentes testes e entre grupos.

vel do presente estudo, recor-

rendo à Análise de Variância

(ANOVA), verificou-se que, genericamente, há diferenças estatisticamente significativas entre o GC1 e o GC, mas não entre os grupos experimentais. Daqui podemos concluir que ambos os programas de treino e desenvolvimento da força abdominal induziram ganhos, mas que a utilização da electroestimulação não se confirmou como um acréscimo em relação ao treino abdominal "convencional".

\section{Correspondência}

Luísa Vieira

E-mail: Ivieira@ismai.pt 